\title{
A Comparative Numerical Study on Heat Transfer Characteristics of a Shell and Tube Heat Exchanger with Segmental and Helical Baffles
}

\author{
Ramtin Barzegarian', Tooraj Yousefi², Alireza Aloueyan ${ }^{3}$ \\ ${ }^{1}$ Department of Mechanical Engineering, Islamic Azad University, Science and Research Branch \\ 14778-93855, Tehran, Iran \\ ramtinbarzegarian@asme.org; tooraj.yousefi@ryerson.ca \\ ${ }^{2}$ Department of Mechanical and Industrial Engineering, Ryerson University \\ ON M5B2K3, Toronto, Canada \\ ${ }^{3}$ Department of Mechanical Engineering, Islamic Azad University, South Tehran Branch \\ Tehran, Iran \\ aaloueyan@gmail.com
}

\section{Extended Abstract}

As their name implies, Heat exchangers are used where is needed to heat transfer between a fluid and a solid object or two or more fluids in order to control the system temperature. In such devices, Heat transfer could be feasible by two ways: direct and indirect contact of fluids. Heat exchangers are very common in many industrial applications such as chemical and petrochemical plants, power stations, refrigeration and air conditioning systems, petroleum refineries, sewage treatment, etc. a good commonplace example of using heat exchangers in our daily life is the car radiator. Shell and tube heat exchangers are the most usual types of heat exchangers in industries which are robust and heavy duty because of their shape (they are typically suitable for higher pressure use). There are various types of baffles for shell and tube heat exchangers such as segmental (single and double segmented baffles), helical, disc and doughnut, etc. which are used to direct the fluid across the tube bundle, reinforce the endurance of long length tubes against sagging and decrease the system's vibration in total. In the recent years, some experimental and computational studies on heat transfer performance of various heat exchangers by changes in their physical specification or in thermo-physical properties of their working fluid were conducted by investigators [1-5]. In the present paper, a computational study of the comparison between using segmental (5 baffles with 1 mm thickness, $30 \mathrm{~mm}$ spacing and 50\% baffle cut) and helical (with tilt angle of $45^{\circ}$, baffle length of $115 \mathrm{~mm}$ and thickness of $1 \mathrm{~mm}$ ) baffles on heat transfer rate of the same shell and tube counter-flow heat exchanger is carried out. The analysis have been accomplished for different Reynolds numbers (turbulent flow condition) of hot water in tubes side ranging from 4516 to 9032. In order to simulate, mesh and analyze the heat transfer apparatus, a commercial computational fluid dynamic (CFD) software (ANSYS Fluent) was adopted. The test section (shell \& tube heat exchanger) with $174 \mathrm{~mm}$ length, consist of 9 stainless steel tubes which were installed with a triangular arrangement. The tubes' inner and outer diameters are 5 and $7 \mathrm{~mm}$ respectively. For shell side, the Inner and the outer diameters are around 33 and $39 \mathrm{~mm}$ respectively. The results demonstrate that the mean overall heat transfer coefficient of the shell and tube heat exchanger with segmental baffles is about $27 \%$ more than that of the same heat exchanger with helical baffle at defined velocity of hot fluid. Also it can be seen that the difference in the overall heat transfer coefficient of mentioned heat exchanger by using two types of baffles, rises with increment of Reynolds number and their values are specified around 13 and $39 \%$ at the minimum and the maximum Reynolds numbers, respectively. Finally, in order to evaluate the accuracy of the simulation, the numerical results were validated with Gnielinski [6] correlation (used for turbulent flow inside a tube) which was illustrated a good agreement between computational and predicted data. 


\section{References}

[1] G.-Y. Zhou, J. Xiao, L. Zhu, J. Wang, S.-T. Tu, "A Numerical Study on the Shell-Side Turbulent Heat Transfer Enhancement of Shell-and-Tube Heat Exchanger with Trefoil-Hole Baffles," Energy Procedia, vol. 75, pp. 31743179, 2015.

[2] R. Barzegarian, M. K. Moraveji, A. Aloueyan, "Experimental investigation on heat transfercharacteristics and pressure drop of BPHE (brazed plate heat exchanger) using TiO2-water nanofluid," Experimental Thermal and Fluid Science, vol. 74, pp. 11-18, 2016.

[3] A. El Maakoul, A. Laknizi, S. Saadeddine, M. El Metoui, A. Zaite, M. Meziane, A. Ben Abdellah, "Numerical comparison of shell-side performance for shell and tube heat exchangers with trefoil-hole, helical and segmental baffles," Applied thermal Engineering, vol. 109, pp. 175-185, 2016.

[4] D. Panahi, K. Zamzamian, "Heat transfer enhancement of shell-and-coiled tube heat exchanger utilizing helical wire turbulator," Applied Thermal Engineering, vol. 115, pp. 607-615, 2017.

[5] R. Barzegarian, A. Aloueyan, T. Yousefi, "Thermal performance augmentation using water based Al2O3-gamma nanofluid in a horizontal shell and tube heat exchanger under forced circulation," International Communications in Heat and Mass Transfer, vol. 86, pp. 52-59, 2017.

[6] V. Gnielinski, "New equations for heat and mass transfer in turbulent pipe and channel flow," Int. Chem. Eng., vol. 16, pp. 359-368, 1976. 